Mariela Pitanga Ramos ${ }^{\mathrm{a}}$

(iD) https://orcid.org/0000-0002-2918-3010

Adauto Emmerich Oliveira ${ }^{a}$

(D) https://orcid.org/0000-0002-9679-8592

Michele Nacif Antunes ${ }^{\mathrm{a}}$

(D) https://orcid.org/0000-0001-8500-8930

a Universidade Federal do Espírito Santo (Ufes), Centro de Ciências da Saúde, Programa de Pós-Graduação em Saúde Coletiva. Vitória, ES, Brasil.

Contato:

Adauto Emmerich Oliveira

E-mail:

adauto.oliveira@ufes.br

Este trabalho é baseado na dissertação de mestrado de Mariela Pitanga Ramos, intitulada Acidente de trabalho ampliado: o rompimento da barragem de Fundão nos jornais impressos do Espírito Santo, apresentada em 2019 à Universidade Federal do Espírito Santo, Vitória, ES, Brasil.

Os autores informam que o trabalho não foi apresentado em evento científico.

Os autores declaram que o trabalho não foi subvencionado e que não há conflitos de interesses.

\section{Acidente de trabalho ampliado: o rompimento da barragem de Fundão nos jornais impressos do Espírito Santo}

\author{
Major work accident: the collapse of the Fundão dam in \\ the newspapers of Espírito Santo, Brazil
}

\section{Resumo}

Introdução: o rompimento da barragem de Fundão (RBF), ocorrido em Minas Gerais, no ano de 2015, se caracteriza como acidente de trabalho ampliado (ATA). Objetivo: elaborar um protocolo e verificar sua aplicabilidade para coleta, classificação e análise de notícias relacionadas a ATA em jornais impressos. Método: estudo descritivo com abordagem qualitativa e quantitativa. A proposta do protocolo foi baseada em informações de literatura científica e em protocolos de análise de notícias utilizados por observatórios de mídia em Saúde. A sua validação foi realizada por meio da sua aplicação na análise da cobertura do RBF efetuada pelos dois principais jornais do Espírito Santo. Resultados: verificou-se ampla cobertura pela mídia, mas com narrativa superficial. O desastre foi naturalizado como ocasionado por intempéries, o sofrimento da população é enfatizado pela diminuição da renda, sendo os aspectos de saúde pouco abordados. Os acidentes e doenças do trabalho não foram retratados como um grave problema de Saúde Pública. Foi constatado que os meios de comunicação destacam mais a cobertura das fases de respostas e reconstrução do que as causas do ATA. Conclusão: o protocolo possibilitou classificar e analisar a abordagem dos jornais, com potencial para ser aplicado em outros casos de ATA de diferentes magnitudes.

Palavras-chave: acidente ampliado; desastre industrial; comunicação em saúde; mídia impressa; saúde do trabalhador.

\begin{abstract}
Introduction: the Fundão Dam failure (FDF), which occurred in Minas Gerais, Brazil, in 2015, is characterized as a major work accident (MWA). Objective: to develop a protocol and verify its applicability for collecting, classifying and analysing news related to MWA in print newspapers. Method: descriptive study with a qualitative and quantitative approach. The protocol proposal was based on information from scientific literature and on protocols used by observatories on health media. Its validation was analyzed by the investigation of the FDF coverage carried out by the two main newspapers of the Espírito Santo State, in Brazil. Results: the accident was widely covered by the media, however, the narratives were superficial. Nature (inclement weather) was commonly mentioned as the main cause of the disaster, the suffering of the population is emphasized by the decrease in income, with health aspects scarcely addressed. Accidents and occupational diseases were not portrayed as a serious public health problem. We found that the media highlighted the coverage of the response and reconstruction phases instead of the real cause of the MWA. Conclusion: the protocol enabled us to classify and analyze the newspapers approach, and showed potentiality to be applied in other MWA cases of different magnitudes.
\end{abstract}

Keywords: major accident; industrial disaster; health communication; print media; occupational health. 


\section{Introdução}

Desde os primórdios da mineração no Brasil, há relatos de acidentes ligados a esta atividade ${ }^{1}$. O surgimento desses acidentes, como acidente industrial ampliado, está diretamente relacionado ao processo de industrialização e ao desenvolvimento de novas tecnologias de produção, surgidos a partir da Revolução Industrial ${ }^{2}$.

Trabalhadores adoecidos e mortos, áreas desmatadas, atropelamento de animais e de pessoas por caminhões e trens, poluição atmosférica, entre outros são exemplos de que a mineração de ferro está repleta de riscos e destruição ${ }^{3}$. Além disso as atividades do processo de mineração geram um grande volume de rejeitos, decorrentes da lavra e beneficiamento, que são acumulados em barragens (temporárias ou definitivas) cuja técnica de construção e manutenção é a mais viável do ponto de vista técnico-econômico ${ }^{4}$.

Os rompimentos dessas barragens transformaram-se em grandes tragédias. Em Minas Gerais (MG), os rompimentos vêm se repetindo com frequência: 2001, 2003, 2007, 2008, 2014, resultando em mortes e destruição ambiental ${ }^{5}$. Em 2015, ocorreu o rompimento da barragem de Fundão (RBF), em Mariana, MG, pertencente a Mineradora Samarco, a qual é controlada pela Vale S.A. e BHP Billiton. Em janeiro de 2019, foi a vez da barragem do Córrego do Feijão, em Brumadinho, MG, considerado um dos eventos mais graves de violação às normas de segurança do trabalho na história da mineração no Brasil ${ }^{5,6}$.

O RBF, que aconteceu em 5 de novembro de 2015, foi considerado o maior desastre socioambiental do Brasil e o maior acidente mundial com barragens de rejeitos de mineração. Sua causa foi resultado de combinação de fatores acumulados ao longo do tempo, cuja origem pode ser explicada por decisões técnico-organizacionais tomadas ao longo da história do sistema ${ }^{7}$.

No dia do rompimento, mais de 600 pessoas, dentre empregados da mineradora e terceirizados, trabalhavam no local ${ }^{8}$. Os impactos foram sentidos ao longo de 663 quilômetros, desde o distrito de Bento Rodrigues, em Mariana, até atingir o mar na vila de Regência, em Linhares, Espírito Santo (ES), totalizando 41 cidades afetadas ${ }^{9}$.

Cabe ressaltar que este desastre foi originado por um processo de trabalho inseguro ${ }^{10}$, causado especificamente por um acidente de trabalho ampliado (ATA), que é caracterizado por extrapolar os limites físicos de responsabilidade da organização, a curto, médio ou longo prazo, causando danos humanos, sociais, culturais, econômicos e ou ambientais, com consequências à saúde física e mental para trabalhadores e trabalhadoras, bem como para a população em geral, de forma imediata ${ }^{11}$. Mais de 10 mil postos de trabalho foram fechados ao longo de toda a bacia do Rio Doce ${ }^{8}$, tendo seu trabalho afetado de forma direta e indireta nas mais diversas atividades produtivas, como a cadeia da mineração, pesca, comércio, turismo, causando impactos sobre os modos de vida dos trabalhadores formais e informais, efetivos e terceirizados, urbanos e rurais ${ }^{12}$.

Esses desastres revelam problemas e desafios no campo da Saúde Coletiva, desde a gestão, licenciamento, fiscalização, monitoramento, até a Vigilância em Saúde e o sistema de emergência do Sistema Único de Saúde (SUS),nas esferas local, estadual e federal. O RBF provocou a morte de 18 pessoas; destas, 13 eram trabalhadores que prestavam serviços à Samarco como terceirizados, 5 moradores de Bento Rodrigues, além de um trabalhador da empresa Samarco que segue desaparecido. No dia do rompimento, mais de 600 pessoas trabalharam no local auxiliando nos resgates ${ }^{13,14}$.

Esse cenário de tragédia e destruição teve grande atenção dos meios de comunicação ${ }^{15}$, mais especificamente pelos jornais impressos dos estados atingidos, que apresentaram uma ampla cobertura sobre os impactos socioambientais ${ }^{16}$. Na medida em que a cobertura jornalística pode influenciar o conhecimento, crenças, valores e comportamentos das pessoas, torna-se relevante analisar seu conteúdo a fim de verificar a qualidade da comunicação e da informação oferecida para a comunidade atingida ${ }^{17}$. Compreender a cobertura nos jornais impressos sobre o ATA da barragem de Fundão pode nos levar a compreender os sentidos dados pelos jornais às causas, responsabilidades, gestão de riscos e de segurança do empreendimento. Diante de diversas perspectivas de abordagens particulares torna-se fundamental desenvolver instrumentos para auxiliar na leitura crítica da mídia ao abordar eventos tão complexos como um ATA.

Assim, o objetivo deste estudo foi elaborar um protocolo para coleta, classificação e análise de notícias relacionadas a ATA em jornais impressos e verificar a sua aplicabilidade a partir da análise da cobertura do RBF nos dois principais jornais do estado do Espírito Santo.

\section{Métodos}

A pesquisa foi realizada em duas etapas. A primeira consistiu em levantamento bibliográfico, a partir das bases de dados da SciELO e BIREME, sobre desastres em suas interfaces com a Saúde do Trabalhador (ST) e com a comunicação na mídia impressa. 
Em paralelo, foi feito um levantamento para identificar os protocolos de análise de notícias desenvolvidos por pesquisadores do Observatório de Saúde nas Mídias do Instituto de Comunicação e Informação Científica e Tecnológica da Fundação Oswaldo Cruz e do Observatório Saúde na Mídia Regional - Espírito Santo (OSM-ES). Após o estudo dos protocolos e da literatura, foi possível adaptar os protocolos já existentes para o campo da ST, com o propósito de incluir temas relacionados a ATA. Foi então elaborado o Protocolo de Coleta e Classificação de notícias sobre ATA, abrangendo elementos que permitem compreender a abordagem dos jornais impressos sobre os acidentes de trabalho ampliado e desastres.

A etapa seguinte compreendeu a validação do protocolo. Para avaliar a sua aplicabilidade, foram selecionados os dois principais jornais impressos do ES: A Gazeta e $A$ Tribuna, com base no número de tiragens anuais e distribuição para todos os municípios do Estado, ambos com sede em Vitória/ES. A coleta foi realizada no OSM-ES, que conta com o acervo dos dois jornais selecionados. O período estipulado foi de 5 de novembro de 2015 a 31 de novembro de 2016, período que compreende a data do rompimento da barragem até um ano após o desastre. Dois pesquisadores fizeram a classificação das notícias. Em seguida, os resultados foram comparados e o protocolo foi validado.
O acervo do OSM-ES está disponível em versão Portable Document Format (PDF) e para a coleta das notícias foi utilizado o sistema de busca do software Adobe Acrobat Reader. Os descritores utilizados para a busca foram "Samarco" e "Rio Doce", uma vez que a Samarco foi a empresa responsável pela operação da barragem de Fundão e o Rio Doce foi o caminho percorrido pelos rejeitos de Minas Gerais até atingir a foz no Espírito Santo. Os arquivos dos jornais, em formato PDF, correspondem a uma página e nessa página pode haver mais de uma matéria. Inicialmente foram levantadas 1.137 páginas de A Gazeta e 1.284 páginas de A Tribuna. Após esta coleta, foram eliminadas as duplicidades, restando um total de 1.911 páginas a serem analisadas, das quais 973 foram do jornal A Gazeta e 938 do jornal A Tribuna. A partir desse corpus foi possível categorizar as notícias de acordo com o Protocolo de Coleta e Classificação de notícias sobre ATA desenvolvido na etapa anterior.

\section{Resultados e discussão}

Para melhor compreensão, o protocolo de coleta e categorização de matérias sobre ATA nos jornais impressos foi dividido em dois blocos. O primeiro compreende a parte estrutural da notícia (Quadro 1) e o segundo está relacionado aos aspectos que abordam o ATA (Quadro 2).

Quadro 1 Protocolo de coleta e classificação de notícias sobre Acidentes de Trabalho Ampliados (ATA) - Parte I -dados sobre o aspecto estrutural da notícia

\begin{tabular}{|c|c|}
\hline Tema & Classificação \\
\hline Jornal & $\begin{array}{l}\text { a) Jornal } 1 \\
\text { b) Jornal } 2 \\
\end{array}$ \\
\hline Descritores: & $\begin{array}{l}\text { a) Descritor } 1 \\
\text { b) Descritor } 2 \\
\end{array}$ \\
\hline Data da publicação & Dia-Mês-Ano \\
\hline Título da matéria & Informar na íntegra \\
\hline Página da publicação & Página em que a matéria foi publicada \\
\hline Chamada de capa & $\begin{array}{l}\text { a) Sim } \\
\text { b) Não }\end{array}$ \\
\hline Gênero textual* & $\begin{array}{l}\text { Informativo } \\
\text { Interpretativo } \\
\text { Opinativo } \\
\text { Diversional } \\
\text { Utilitário } \\
\end{array}$ \\
\hline Editoria & A editoria da publicação varia de acordo com o jornal analisado. \\
\hline Elementos complementares de edição & $\begin{array}{l}\text { a) Fotografia; } \\
\text { b) Infográfico; } \\
\text { c) Tabela ou box; } \\
\text { d) Ilustração; } \\
\text { f) Gráfico; } \\
\text { g) Não se aplica }\end{array}$ \\
\hline
\end{tabular}

" Informativo: vigilância social; Opinativo: fórum de ideias; Interpretativo: papel educativo, esclarecedor; Diversional: distração, lazer; Utilitário: auxílio nas tomadas de decisões cotidianas.

Fonte: Protocolo adaptado Observatório de Saúde nas Mídias do Instituto de Comunicação e Informação Científica e Tecnológica da Fundação Oswaldo Cruz e do Observatório Saúde na Mídia Regional - Espírito Santo (OSM-ES) 
Quadro 2 Protocolo de Coleta e Classificação de notícias sobre Acidentes de Trabalho Ampliados (ATA) Parte II -dados sobre o ATA

\begin{tabular}{|c|c|}
\hline Tema & Classificação \\
\hline Denominação do fato & $\begin{array}{l}\text { Acidente } \\
\text { Catástrofe } \\
\text { Crime } \\
\text { Desastre } \\
\text { Incidente } \\
\text { Tragédia } \\
\text { Outras } \\
\end{array}$ \\
\hline $\begin{array}{l}\text { Visibilidade aos trabalhadores que atuaram nas ações de } \\
\text { socorro e resgate após o desastre }\end{array}$ & $\begin{array}{l}\text { Sim } \\
\text { Não } \\
\end{array}$ \\
\hline Ramos de atividades afetados & $\begin{array}{l}\text { Pesca } \\
\text { Agricultura } \\
\text { Turismo } \\
\text { Comércio } \\
\text { Indústria da Mineração } \\
\text { Outros (descrever) } \\
\end{array}$ \\
\hline Impactos na saúde pública & $\begin{array}{l}\text { Atendimentos de emergência } \\
\text { Óbitos } \\
\text { Ferimentos/Doenças (descrever patologias citadas) } \\
\text { Sofrimento psíquico }\end{array}$ \\
\hline Impactos na saúde do trabalhador & $\begin{array}{l}\text { Óbitos } \\
\text { Dermatoses } \\
\text { Transtorno psíquico } \\
\text { Outros (descrever) } \\
\end{array}$ \\
\hline Riscos ocupacionais decorrentes do acidente & $\begin{array}{l}\text { a) Acidentes típicos } \\
\text { b) Químicos } \\
\text { c) Físicos } \\
\text { d) Biológicos }\end{array}$ \\
\hline Impactos socioambientais & $\begin{array}{l}\text { a) Fauna e Flora } \\
\text { b) Contaminação ambiental (solo, ar e hídrica) } \\
\text { c) Lazer } \\
\text { d) Produção e consumo de alimentos } \\
\text { e) Emprego e renda } \\
\text { f) Outros (descrever) }\end{array}$ \\
\hline
\end{tabular}

Fonte: Protocolo desenvolvido para a pesquisa

A elaboração do Quadro 1, sobre a parte estrutural da notícia, buscou fornecer subsídios para a padronização da análise da produção noticiosa e dos parâmetros de circulação da informação nos jornais ${ }^{18}$.

A aplicação do Quadro 1 possibilitou conhecer como o tema foi apresentado pelos jornais impressos, visto que os acontecimentos que ganham destaque são influenciados por elementos estruturantes da noticiabilidade, como exemplo, a notoriedade dos envolvidos; a proximidade dos leitores em termos geográficos; a relevância, que corresponde à preocupação de informar ao público acontecimentos que são importantes por terem impacto direto sobre a vida das pessoas; e a novidade, como questão central do assunto ou do fato ${ }^{19}$.

A primeira categoria de análise da parte estrutural da notícia, selecionada para fins deste estudo, foi o gênero textual. Para a análise do estudo, foram selecionadas apenas as matérias do gênero informativo; a opção por esses gêneros textuais se justifica por serem os que melhor descrevem os fatos e aprofundam a análise das informações e da aplicabilidade do protocolo e suas interfaces com o ATA ${ }^{20}$.

Para o gênero textual, foi considerada a classificação sugerida por Melo e Assis ${ }^{20}$, que propõem um modelo arraigado em uma perspectiva comunicacional e atento aos rituais peculiares do Jornalismo. Os gêneros são divididos em: a) informativo (nota, notícia, reportagem, entrevista); b) opinativo (editorial, comentário, artigo, resenha, coluna, crônica, caricatura, carta); c) interpretativo (perfil, enquete, cronologia, dossiê); d) diversional (história de interesse humano; e) utilitário (cotação, roteiro, serviço) ${ }^{20}$.

As matérias classificadas como o gênero informativo totalizaram 671 no jornal A Gazeta e 824 no jornal $A$ Tribuna. Em relação ao volume de matérias, foi possível notar a ampla cobertura no primeiro mês nos dois jornais analisados, conforme Figura 1. 


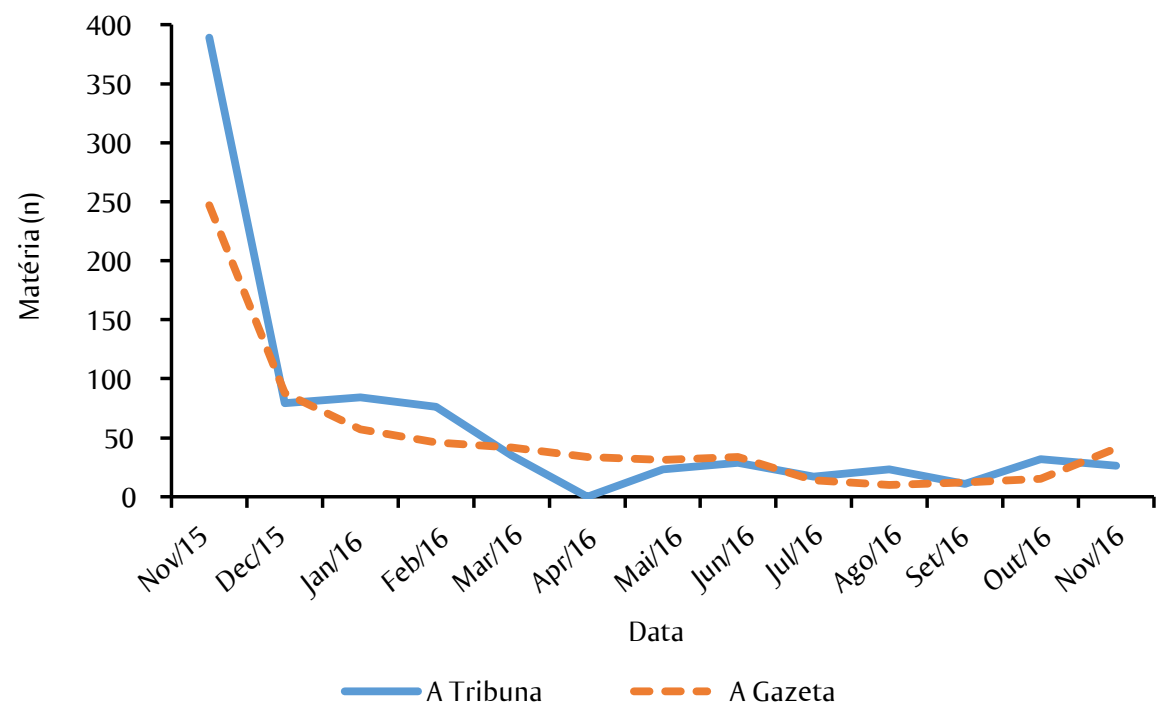

Figura 1 Quantidade de matérias jornalísticas sobre o rompimento da barragem de Fundão, em Mariana, MG, publicadas de novembro de 2015 a novembro de 2016, nos jornais A Gazeta e A Tribuna, Espírito Santo, Brasil

A partir da leitura das matérias, observou-se que o início da cobertura jornalística no ES foi caracterizado pela busca das causas do RBF e por narrativas dos danos causados. Esse resultado está em consonância com a pesquisa apresentada por Bueno ${ }^{21}$, que analisou a cobertura do primeiro mês após o RBF por quatro jornais brasileiros de grande circulação: Folha de S. Paulo, O Estado de S. Paulo, O Globo e Valor Econômico, evidenciando uma cobertura expressiva também na mídia nacional.

Como também pode ser observado na Figura 1, o tema não saiu da pauta ao longo do ano, com exceção do mês de abril de 2016, quando não houve registro de matéria sobre o tema no Jornal A Tribuna. A diminuição de matérias pode ser justificada pela cultura jornalística que valoriza os acontecimentos extraordinários, relacionada com a noticiabilidade. Esse conceito é definido como o "conjunto de critérios e operações que fornecem a aptidão de merecer um tratamento jornalístico, isto é, possuir valor como notícia"18. Desta forma, a partir da leitura do cenário durante os primeiros meses da cobertura analisada, foi possível verificar que a medida que o tempo foi passando, outros assuntos ganharam mais destaque e ocuparam a pauta dos jornais: os escândalos de corrupção e a abertura de impeachment da Presidente Dilma, a epidemia de Zika, a seca no Brasil, as Olimpíadas, entre outros temas.

Vale destacar o cenário em que se constituiu o jornalismo no ES. De acordo com Silva et al. ${ }^{22}$, tradicionalmente considerava-se que o jornal A Gazeta destinava suas matérias prioritariamente a um público mais elitizado e, portanto, constituía-se em um jornal mais conservador. Em contrapartida, o jornal $A$ Tribuna teria um foco maior nas classes mais populares. Entretanto, afirmam os autores, esses perfis têm se confundido na atualidade devido à precariedade das próprias redações e às reformulações estéticas e editoriais ocorridas ao longo dos anos. Por isso, cada vez mais esses periódicos têm se apresentado com abordagens semelhantes, homogêneas e similares, dificultando a distinção de um perfil elitista ou popular ${ }^{22}$.

Gentilli e Guerra ${ }^{23}$, ao buscar vestígios das dinâmicas editoriais dos jornais impressos capixabas no século XX, analisam os movimentos de popularização das linhas editoriais e concluem que as transformações políticas, econômicas, sociais e culturais produziram um novo consumidor de notícias, e que os jornais precisaram se adequar a essa realidade. Os autores observaram como decisões mercadológicas impactaram diretamente sobre o conteúdo editorial dos jornais, moldando-o na tentativa de agradar o leitor; consequentemente, concluem os autores que, apesar dos movimentos realizados pelos jornais capixabas para sobreviver às mudanças estruturais do jornalismo vivenciadas na passagem do século XX para o XXI, os últimos anos mostram que os jornais estão pouco a pouco perdendo seu espaço na vida do capixaba ${ }^{23}$. Somando a isso, o estudo realizado por Rebouças e Caldas ${ }^{24}$, aponta que, entre 2011 e 2016, A Tribuna teve uma queda de $45 \%$ na sua circulação, de acordo com o Instituto Verificador de Circulação (IVC), e para A Gazeta essa queda foi de $53 \%$. Soma-se a este cenário, a queda do número 
de páginas dos dois jornais, a demissão de profissionais e os atrasos de salários ${ }^{24}$.

Aliado à cronologia, alguns outros critérios jornalísticos valorizam a cobertura, atuando como critérios de hierarquização, como por exemplo: chamada de capa; publicação em página ímpar; presença de elementos de edição entre outros ${ }^{19}$. Identificar a numeração da página em que a matéria foi publicada é importante uma vez que as matérias mais relevantes, na maioria das vezes, são publicadas nas páginas ímpares, pois são elas que atraem mais a atenção do leitor ${ }^{25}$. Na temática estudada, ambos os jornais apresentaram 54\% das matérias em páginas pares (A Gazeta, 360 matérias e A Tribuna, 444 matérias), o que indica uma menor valorização do tema por parte dos jornais.

Em relação à chamada de capa, cabe ressaltar que a primeira página de um jornal pode informar sobre seus objetivos e sobre a maneira como cada diário se posiciona política, cultural e socialmente ${ }^{26}$. Além disso, considera-se que a capa provoca o leitor a interessar-se pelo seu conteúdo ${ }^{27}$.

Dessa forma, neste estudo, a análise da chamada de capa foi considerada relevante para compreender como os jornais atuaram na abordagem do tema. Quanto às chamadas de capa, o jornal A Gazeta publicou 52 chamadas, enquanto $A$ Tribuna, um total de 19 . O primeiro mês, novembro de 2015, foi aquele que concentrou as chamadas de capas (A Tribuna, 19 e A Gazeta, 13). Considera-se que o destaque do primeiro mês está relacionado com a expectativa da chegada da onda de rejeitos ao estado do ES, uma vez que a previsão dos especialistas era a chegada ao estado em 9 de novembro, entretanto só chegou sete dias depois, sendo que no dia 21 de novembro o rejeito alcançou a foz do rio, onde houve o encontro com o mar ${ }^{12}$.

A partir da aplicação do protocolo, aliado à leitura das matérias selecionadas dos jornais, foi possível identificar que as chamadas de capa deram destaque principalmente às consequências da enxurrada de "lama" para o Rio Doce, com fotos, com teor de preocupação pela contaminação e emoção pelos danos à comunidade. Ao lançarmos o olhar para o termo "lama", observa-se uma excessiva utilização pelos jornais em substituição ao que realmente contaminou o rio Doce, os rejeitos da mineração ${ }^{28}$. Seu uso causa incômodo e é questionado pelos atingidos, pois, para eles, o termo lama, sendo uma mistura de argila e água, tem uma percepção poética de construção e pureza, em oposição à destruição causada pelo desastre com o rejeito, conforme apontou uma das lideranças de Regência durante o evento no ES que discutiu a invisibilidade e resistência dos atingidos ${ }^{29}$.

Em relação às editorias dos jornais, a classificação foi estabelecida conforme a especificidade de cada um deles (Tabela 1); o jornal A Gazeta não possui as editorias "Ciência e Tecnologia" e "Regional". Como pode ser observado, os dois jornais trouxeram a discussão para variadas editorias, porém a cobertura foi centralizada na editoria "Cidades", que retrata o cotidiano das cidades do ES atingidas pelo rompimento da barragem e suas consequências sociais, sanitárias, ambientais, econômicas, entre outras. No que diz respeito à editoria "Economia", os jornais retrataram os impactos na arrecadação no ES com a paralisação das atividades da Samarco e como os municípios afetados foram afetados direta e indiretamente. Enquanto, a parte de "Política" retratou as reuniões de comissões ou gastos de parlamentares com as discussões sobre o RBF. A diversidade de editorias apresentadas neste estudo está em consonância também com os resultados apresentados em outra pesquisa ${ }^{21}$, que descreve a magnitude do RBF como de repercussão múltipla e como um tema transversal e multidisciplinar.

Em relação aos elementos complementares de edição das matérias analisadas, a maior parte possuía em seu texto fotografias, gráficos, ilustrações, infográficos e mapas. A fotografia foi a forma de representação visual mais utilizada, aparecendo 454 vezes em A Gazeta e 558 vezes em A Tribuna, o que se justifica pelos sentidos carregados pelas fotografias, com função e intenção ao serem inseridas na matéria ${ }^{30}$. Um olhar geral sobre as fotografias permite observar que a coloração "alaranjada" da água teve destaque entre as imagens, assim como a representação do sofrimento social da população vítima do RBF.

No que diz respeito a segunda parte do protocolo, destacam-se os temas relacionados ao acidente de trabalho ampliado (Quadro 2).

Tabela 1 Quantitativo de matérias abordando o rompimento da Barragem do Fundão, publicadas nos jornais A Gazeta e A Tribuna, segundo tipo de Editoria. Espírito Santo, Brasil, novembro de 2015 a novembro de 2016

\begin{tabular}{|c|c|c|}
\hline Editorias & A Gazeta & A Tribuna \\
\hline Cidades & 527 & 302 \\
\hline Economia & 54 & 147 \\
\hline Especial & 25 & 247 \\
\hline Política & 12 & 31 \\
\hline Mundo & 1 & - \\
\hline Regional & - & 75 \\
\hline Ciência e tecnologia & - & 3 \\
\hline
\end{tabular}


Com relação ao item "denominação do fato" (acidente, catástrofe, crime, desastre, incidente, tragédia e outros), os jornais trouxeram variações diversas na forma de nomear o acidente ampliado, incluindo alternâncias de termos em uma única matéria. Isso pode estar relacionado aos interesses comerciais que atravessam o jornalismo ${ }^{31}$, considerando que a Samarco/Vale S.A./BHP Billiton são grandes anunciantes dos jornais analisados. A maior parte das matérias não trouxe uma designação para a tragédia e sim uma forma de narração do acontecimento para nomeá-lo, tais como "rompimento da barragem", "chegada da lama", "mar de lama", entre outros. Cabe ressaltar que a denominação do rompimento da barragem pode trazer discussões que, por meio de seu enquadramento, pode problematizar as responsabilidades das empresas privadas como também do poder público e não só insistir nos danos e na emocionalidade dos atingidos ${ }^{32}$.

O uso do termo "desastre" teve destaque nas matérias dos dois jornais analisados. Desastre é um acontecimento coletivo trágico nos quais há perdas e danos súbitos e involuntários que desorganizam o modo de vida de uma coletividade ${ }^{33}$. O que deve ser levado em consideração é que esse termo tende a naturalizar o RBF, uma vez que sua causa poderia ser atribuída a intempéries da natureza. Fato esse defendido inicialmente pela empresa Samarco/Vale S.A./ BHP Billiton, que já tinham conhecimento prévio de problemas que poderiam levar ao RBF, ignorando os laudos do Ministério Público que demonstravam que as estruturas das barragens estavam comprometidas antes do acidente ${ }^{34}$.

Aliado a isso, foi lançado pelo governo federal o Decreto 8.276, de 13 de novembro de 2015, considerando o rompimento de barragens como desastre natural, com o objetivo de possibilitar o saque do Fundo de Garantia por Tempo de Serviço (FGTS) do trabalhador diante do rompimento de barragens. $\mathrm{O}$ fato de nomear como desastre natural foi interpretado como uma afronta pelos atingidos tendo em vista que as causas do rompimento foram a precariedade nas condições de segurança da barragem ${ }^{35}$.

O termo "acidente" apareceu nas matérias com narrativas feitas pelas empresas responsáveis e nas matérias que abordaram as indenizações e responsabilizações.

Além disso, as classificações referentes à denominação do ATA encontradas apareceram adjetivadas de várias formas: ambiental, não natural, ecológico, catastrófico, hídrico, humanitário, socioambiental. Essas variações mostram que o texto jornalístico utiliza diferentes códigos semiológicos, os quais são combinados com os recursos técnicos e tecnológicos disponíveis ${ }^{36}$, ou seja, usam sistemas de linguagem na relação entre o emissor e o receptor que exprimem ideias no seio da vida social dos sujeitos. É interessante notar que o vínculo causal com o trabalho (e mesmo com o ambiente) é omitido ou secundarizado, descaracterizando, assim, sua gênese social específica ${ }^{10}$.

Para que se possa compreender a visibilidade dada ao trabalhador que atuou nas ações de socorro e resgate após o desastre é preciso compreender a interferência que a invisibilidade social, no âmbito do trabalho, causa nas pessoas. Nesta pesquisa, parte-se do princípio de que o trabalho executado é algo muito maior que a execução de uma função, atuando como apoio à construção da identidade dos seres humanos, e que é preciso um acompanhamento pós-desastre desse trabalhador ${ }^{36}$. Os trabalhadores dos diversos setores que se mobilizaram para atuar no enfrentamento da tragédia podem desenvolver quadros de sofrimento, adoecimento físico e psíquico, em função da situação emergencial e da penúria à qual ficam submetidas as populações atingidas ${ }^{10}$.

Em relação ao tema "visibilidade ao trabalhador que atuou no socorro e resgate no desastre", o jornal A Gazeta apresentou um total de 41 matérias sobre o assunto e $A$ Tribuna, 46 matérias, com a soma de ambos correspondendo a $6 \%$ do total. As matérias fizeram referência aos trabalhadores bombeiros, do exército e voluntários que atuaram no resgate de pessoas e animais, na sua jornada exaustiva nas buscas por sobreviventes, no abalo emocional desses trabalhadores devido à magnitude dos danos e aos trabalhadores da Samarco que estavam em atividade durante o rompimento da barragem. A partir daí surgem questionamentos: existe alguma instituição preparada para assumir a centralização de ações relacionadas aos traumas pós tragédia? Quais seriam as articulações necessárias para lidar com esse contexto? Haverá um acompanhamento dos profissionais que tiveram contato com os rejeitos?

Um outro tema evidenciado no protocolo foi a questão da territorialidade, na qual os municípios atingidos constituíram seus lugares e modo de vida em torno da dinâmica fluvial e, após a inserção do complexo minerário, seus territórios foram transformados em áreas de risco $^{37}$. Essa abordagem leva em conta uma perspectiva inter e transdisciplinar, na qual a saúde pode e deve ser associada aos processos produtivos ${ }^{38}$.

Logo, conhecer os ramos de atividade afetados possibilitaria a elaboração de um diagnóstico situacional da Saúde do Trabalhador no território, o que permitiria listar: quem, quantos e quais são os riscos e perigos a que estão sujeitos com o contato com os rejeitos, o que fazem e de que adoecem e morrem os trabalhadores, ou seja, o perfil produtivo e o perfil epidemiológico dos agravos relacionados ao trabalho, além de analisar a capacidade instalada dos municípios para o 
atendimento aos trabalhadores, as pactuações de procedimentos, entre outras questões ${ }^{39}$.

Os "ramos de atividades afetados" pelo RBF foram retratados em $40 \%$ das matérias analisadas de ambos os jornais. Em $A$ Gazeta foram retratados em 271 matérias e em A Tribuna, 326 matérias, conforme Tabela 2. Nos dois jornais, as atividades mais abordadas foram pesca/aquicultura e indústria extrativa/ mineração. A primeira atividade envolve a pesca de peixes e mariscos no rio e no mar, cata de crustáceos nos mangues, comercialização do pescado e outras envolvidas na atividade pesqueira. E a segunda atividade engloba toda a cadeia produtiva da mineração, desde o processo de extração até a pelotização do minério para exportação. Outras atividades, como a agricultura, foram afetadas de forma direta por problemas de contaminação da água para irrigação e do solo, além do turismo e da hotelaria, lazer e recreação e do comércio, que sofreram com a falta de balneabilidade das praias ou paralisação de atividades da Samarco.

Em relação ao tema "riscos ocupacionais", nenhum dos dois jornais abordou os riscos para o trabalhador presentes na mineração. O rompimento da barragem também não foi mencionado como um acidente de trabalho, embora 14 trabalhadores da empresa Samarco tenham sido vitimados no evento ${ }^{39}$.

Quanto aos impactos na saúde do trabalhador, A Gazeta fez referência ao tema em 11 matérias, mencionando os óbitos de trabalhadores.Com relação aos "riscos ocupacionais decorrentes do acidente", apenas em duas matérias o tema foi abordado: em uma, relacionada a risco químico, orientava a população de trabalhadores da agricultura a usar equipamentos de proteção individual (EPI) para utilizar a água para irrigação, e, em outra, apontou risco de um novo acidente de trabalho durante os resgates, o que, após emissão de um alerta, paralisou as buscas por vítimas e desaparecidos na região. O jornal $A$ Tribuna citou os óbitos de trabalhadores em 19 matérias, porém em uma abordagem pela via de tragédia e não como acidente de trabalho na atividade da mineração. Acreditamos que a pouca visibilidade dos aspectos relacionados à saúde e segurança do trabalhador encontrado nos jornais do ES pode estar relacionada ao defendido por Lacaz, Porto e Pinheiro ${ }^{40}$, os quais apresentam que o poder das grandes empresas, sobretudo em pequenos municípios, tende a exercer forte domínio econômico, social, simbólico e político sobre instâncias de representação, associações e moradores locais, o que enfraquece a mobilização e combatividade. Além disso, o episódio permitiu saber que a Samarco operava com mais de 13 empresas terceirizadas por ocasião da tragédia. Essa segmentação, com a consequente fragmentação dos trabalhadores, impõe limites à ação e ao empoderamento de seus sindicatos em relação à temática ${ }^{40}$.

Tabela 2 Quantitativo de matérias abordando o rompimento da Barragem do Fundão, publicadas nos jornais A Gazeta e A Tribuna, segundo ramos de atividades atingidos pelo acidente. Espírito Santo, Brasil, novembro de 2015 a novembro de 2016

\begin{tabular}{|c|c|c|}
\hline Ramos de atividades & A Gazeta & A Tribuna \\
\hline Agricultura & 38 & 12 \\
\hline Artesanato & 5 & 0 \\
\hline Atividades domésticas & 6 & 2 \\
\hline Comércio & 24 & 55 \\
\hline Educação & 3 & 0 \\
\hline Exportação & 6 & 0 \\
\hline Extração de areia & 7 & 1 \\
\hline Indústria & 5 & 6 \\
\hline Indústria extrativa/mineração & 86 & 154 \\
\hline Lazer e recreação & 13 & 2 \\
\hline Pecuária/criação de animais & 12 & 26 \\
\hline Pesca/aquicultura e afins & 129 & 97 \\
\hline Transporte ferroviário & 1 & 5 \\
\hline Turismo e hotelaria & 24 & 45 \\
\hline
\end{tabular}


Diante deste cenário, o RBF foi considerado um ATA, pois os seus danos ultrapassam os limites da empresa, com consequências socioambientais. Portanto, torna-se imprescindível, compreender os impactos do desastre em si. Dessa forma, a classificação do tema "impactos socioambientais" foi feita de forma sucinta, baseada na literatura científica e relatórios, sabendo que a magnitude de um acidente ampliado não delimita de forma evidente todos os efeitos dele decorrentes, pois sua complexidade não permite enxergar com transparência absoluta todos os possíveis resultados e particularidades que podem atingir a sociedade ${ }^{12}$.

Os impactos socioambientais foram evidenciados em 97\% das matérias de ambos os jornais (A Gazeta, 669 matérias e $A$ Tribuna, 802 matérias). $O$ destaque foi o drama da "morte" do Rio Doce frente ao volume de rejeitos até sua chegada ao mar e a destruição ao longo de seu curso, como a da biodiversidade da fauna e flora. A interrupção de captação e distribuição de água foi representada pela escassez de água, o que refletiu nos modos diários e nas atividades relacionadas à utilização de recursos hídricos, além da desconfiança por parte da população e gestores públicos frente aos diversos laudos apresentados sobre a qualidade da água.

Considerando a importância do tema em pauta ao longo do período estudado e diante dos dados apresentados, verificamos que o protocolo possibilitou analisar a cobertura do RBF pela mídia impressa a partir dos aspectos que envolvem um ATA. Foi possível observar que a saúde e segurança do trabalho foram temas poucos abordados pelos jornais do Espírito Santo no período estudado. Anualmente, no Brasil, os acidentes de trabalho matam e mutilam centenas de pessoas, porém não se vê grande repercussão. De acordo com os últimos dados publicados pelo Ministério da Fazenda, por meio do Instituto Nacional do Seguro Social (INSS) ${ }^{41}$, em 2017 foram registrados 549.405 acidentes de trabalho em todo o país, correspondendo apenas aos trabalhadores formais que contribuem para a Previdência Social. Ou seja, este número pode ser ainda maior quando se sabe que o total de trabalhadores informais em 2017 representou 40,8\% de toda a população ocupada (que exerce alguma atividade remunerada) no país, de acordo com o IBGE ${ }^{42}$. Logo, é válido que haja circulação e apropriação de informação sobre Saúde e Segurança do Trabalhador, para que se abra discussão entre a população.

\section{Conclusão}

Na atualidade, para pensar em saúde do trabalhador torna-se necessário compreender também as contradições que residem no contexto do crescimento econômico brasileiro. A atividade mineradora desempenha importante papel na sociedade, entretanto sua exploração de maneira não responsável e planejada, além de pouco esforço dos gestores em mitigar os riscos, vem causando consecutivos acidentes de trabalho ampliados, com consequências de grandes proporções. Assim, cada vez mais, as informações sobre os riscos de barragens, seja ela de rejeitos, ou seja, de água, devem circular entre a população, na tentativa de se fazer exigir o cumprimento de leis e normas específicas, ampliando a discussão para além de respostas, criando de fato uma cultura de risco e prevenção.

A partir de uma leitura crítica dos jornais impressos, os dados encontrados mostraram uma ampla cobertura no ES, um dos estados atingidos pelo rompimento da barragem. No entanto, há uma narrativa dos fatos com um olhar superficial na tentativa de naturalização do desastre como algo ocasionado pelas intempéries da natureza. O sofrimento da população foi apresentado com ênfase na diminuição da renda de quem dependia do Rio Doce para sobreviver, bem como o impacto sobre as empresas e prestadores de serviços que tiveram suas atividades paralisadas com a interrupção de funcionamento da Samarco no ES. Os aspectos de saúde da população foram pouco abordados, os trabalhadores pouco evidenciados pela cobertura, mesmo tendo sido o RBF decorrente de um ATA.

Nesse sentido, a elaboração de um protocolo de coleta e classificação de matérias relacionadas ao ATA nos jornais impressos permitiu conhecer a abordagem dos jornais sobre os impactos nos processos de saúde da população, de saúde e segurança do trabalhador. Foi possível observar que os acidentes e doenças do trabalho não são retratados como um grave problema de Saúde Pública, nem mesmo os acidentes de trabalhos ampliados com múltiplas vítimas e impactos ambientais. Dessa forma, os acidentes de trabalho ampliados devem ser retratados pelos meios de comunicação em sua origem, suas causas, e não só na cobertura das fases de respostas e reconstrução.

Concluindo, essa pesquisa não buscou esgotar todas as possibilidades que os estudos sobre os enquadramentos dados sobre o acidente de trabalho ampliado. O contato com a quantidade de material noticioso produzida sobre o caso específico do RBF se mostra uma janela aberta para futuros estudos acadêmicos sobre a cobertura dos jornais impressos em ocorrências de ATA, podendo ser aplicado em outros casos, de diferentes magnitudes, com responsabilidade e ética. 


\section{Contribuições de autoria}

Os autores contribuíram igualmente para diversas fases da investigação e da redação do artigo incluindo o desenho da pesquisa, a coleta e análise dos dados e a redação, revisão e aprovação do texto para publicação e assumem integral responsabilidade pelo estudo e pelo conteúdo aqui publicado.

\section{Referências}

1. Brant AC, Vieira M. Sem plano de emergência mortes na mineração acende alerta em Minas [Internet]. Brasil de Fato. 2015 [citado em 6 nov 2020]. Disponível em: https://www.em.com.br/app/ noticia/gerais/2015/11/20/interna_gerais,709937/ sinonimo-de-perigo.shtml

2. Freitas CM, Porto MFS, Machado JMH. Acidentes industriais ampliados: desafios e perspectivas para o controle e a prevenção. Rio de Janeiro: Fiocruz; 2000.

3. Porto MFS. A tragédia da mineração e do desenvolvimento no Brasil: desafios para a saúde coletiva. Cad Saude Publica. 2016;32(2):e00211015.

4. Souza TF Jr, Moreira EB, Heineck KS. Barragens de Contenção de Rejeitos de Mineração no Brasil. Holos. 2018;5:2-39

5. Beltrami AC, Freitas CM, Machado JHM. Acidentes com produtos perigosos no Brasil, no período 20062009: análise dos dados dos sistemas de informações como subsídio às ações de vigilância em saúde ambiental. Epidemiol Serv Saude. 2012;21(3):439-48.

6. Ministério Público do Trabalho 3a Região (BR). Atuação do MPT em Minas nos casos de Mariana e Brumadinho [Internet]. Belo Horizonte; 2019 [citado em 20 abr 2019]. Disponível em: http:// www.prt3.mpt.mp.br/informe-se/noticias-do-mptmg/1072-barragens

7. Wanderley LJ, Mansur MS, Milanez B, Pinto RG. Desastre da Samarco/Vale/BHP no Vale do Rio Doce: aspectos econômicos, políticos e socio ambientais. Cienc Cult. 2016;68(3):30-3.

8. Faria MP, Botelho MR. A análise da causalidade do "acidente" de trabalho da Samarco. In: Pinheiro TMM, Polignano MV, Goulart EMA, Procópio JC. Mar de lama da Samarco na bacia do rio Doce: em busca de respostas. Belo Horizonte: Instituto Guaicuy; 2019. p. 50-63.

9. Ministério do Trabalho e Previdência Social (BR). Superintendência Regional do Trabalho e Emprego em MG. Relatório de análise de acidente rompimento da barragem de rejeitos Fundão em Mariana - MG. Belo Horizonte; 2016.

10. Pinheiro TMM, Silva JM. O caso Samarco: um "acidente de trabalho ampliado? In: Pinheiro TMM, Polignano MV, Goulart EMA, Procópio JC. Mar de lama da Samarco na bacia do rio Doce: em busca de respostas. Belo Horizonte: Instituto Guaicuy; 2019.
11. Lima AA, Freitas M. Os impactos à saúde dos trabalhadores e da população atingida pelo acidente de trabalho ampliado da Samarco, Vale e BHP Billiton. In: Pinheiro TMM, Polignano MV, Goulart EMA, Procópio JC. Mar de lama da Samarco na bacia do rio Doce: em busca de respostas. Belo Horizonte: Instituto Guaicuy; 2019. p. 161-79.

12. Organon Núcleo de Estudo, Pesquisa e Extensão em Mobilizações Sociais. Impactos socioambientais no Espírito Santo da ruptura da barragem de rejeitos da Samarco: relatório preliminar. Vitória: Organon; 2015.

13. Fundação Oswaldo Cruz. Centro de Estudos e Pesquisas em Emergências e Desastres em Saúde. Fortalecimento das capacidades de prontidão e resposta frente a situações de emergência de interesse de saúde pública: Espírito Santo e Vitória. Rio de Janeiro: Fiocruz; 2013

14. Porto MFS. A tragédia da mineração e do desenvolvimento no Brasil: o desafio para a saúde coletiva. Cad Saude Publica. 2016;32(2):e00211015.

15. Santos CMM, Falco A. O caso de Mariana-MG: análise da cobertura midiática sobre o maior desastre ambiental do Brasil. In: Anais do XXII Congresso de Ciências da Comunicação na Região Sudeste [Internet]; 22-24 jun 2017; Volta Redonda. São Paulo: Intercom; 2017 [citado em 20 set 2019]. Disponível em: http://portalintercom.org.br/anais/ sudeste2017/resumos/R58-0735-1.pdf

16. Espindola HS, Nodari ES, Santos MA. Rio Doce: riscos e incertezas a partir do desastre de Mariana (MG). Rev Bras Hist. 2019;39(81):141-62.

17. Gomes RAL. A comunicação como direito humano: um conceito em construção. Recife [dissertação]. Recife: Universidade Federal de Pernambuco; 2007.

18. Coqueiro JM, Cavaca AG, Emerich TB, Antunes MN, Oliveira AE, Figueiredo TAM. Diabetes mellitus na mídia impressa: uma proposta de protocolo de coleta e classificação de dados para pesquisa. Rev Bras Pesqui Saude. 2018;20(2):74-8.

19. Traquina N. Teorias do Jornalismo, volume II: A tribo jornalística - uma comunidade interpretativa transnacional. $2^{\text {a }}$ ed. Florianópolis: Insular; 2008.

20. Melo JM, Assis F. Gêneros e formatos jornalísticos: um modelo classificatório. Rev Bras Cien Comun. 2016;39(1):39-56. 
21. Bueno WC. A cobertura jornalística de catástrofes ambientais: entre a vigilância e a espetacularização da notícia. Comun Soc. 2017;39(1):21-41.

22. Silva TM, Prado HV, Emerich TB, Cavaca AG, Oliveira AE, Gentilli V. A saúde e o Sistema Único de Saúde nos bastidores da imprensa: o que os jornalistas têm a nos dizer? Rev Bras Pesqui Saude. 2018;20(2):64-73.

23. Gentilli V, Guerra J. Jornais capixabas no século XXI: uma guinada ao popular. In: Anais do $15^{\circ}$ Encontro Nacional de Pesquisadores em Jornalismo; 2017; São Paulo. São Paulo: Associação Brasileira de Pesquisadores em Jornalismo; 2017.

24. Rebouças E; Caldas W. Os jornais podem (e já começaram a) desaparecer. In: Anais do $39^{\circ}$ Congresso Brasileiro de Ciências da Comunicação [Internet]; 2016; São Paulo. São Paulo: Intercom; 2016 [citado em 20 set 2019]. Disponível em: http://portalintercom.org.br/anais/nacional2016/ resumos/R11-2059-1.pdf

25. Folha de S. Paulo. Círculo Folha [Internet]. São Paulo; 2001 [citado em 27 jun 2017]. Disponível em: https://www1.folha.uol.com.br/folha/circulo/ manual_edicao_p.htm

26. Medeiros FNS, Ramalho M, Massarani L. A ciência na primeira página: análise das capas de três jornais brasileiros. Hist Cienc Saude-Manguinhos. 2010;17(2):439-54.

27. Gruszynski AC. A forma que (in)forma: o projeto gráfico do jornal Impresso na contemporaneidade. In: Anais do $34^{\circ}$ Congresso Brasileiro de Ciências da Comunicação; 2011; Recife. São Paulo: Intercom; 2011. p. 1-16.

28. Vervloet RJHM. Geomorfologia da região de rompimento da barragem da Samarco: da originalidade da paisagem à paisagem da mineração. In: Milanez B, Losekann C. Desastre no Vale do Rio Doce: antecedentes, impactos e ações sobre a destruição. Rio de Janeiro: Folio Digital: Letra e Imagem; 2016. p. 91-124.

29. Vídeo Saúde Regional UFES/ES. Rio Doce: Tragédia e resistências [Internet]. [Vitória]: UFES; 23 fev 2019 [citado em 6 nov 2020]. Vídeo: 19 min. Disponível em: https://youtu.be/3eNHj8PNWQk

30. Tavares FMB, Vaz PBF. Fotografia jornalística e mídia impressa: formas de apreensão. Famecos. 2005;12(27):125-38.
31. Emerich TB. Interfaces da comunicação e saúde na mídia impressa [dissertação]. Vitória: Universidade Federal do Espírito Santo; 2015.

32. Zhouri A, Oliveira R, Zucarelli M, Vasconcelos M. O desastre do Rio Doce: entre as políticas de reparação e a gestão das afetações. In: Zhouri A. Mineração, violências e resistências: um campo aberto à produção do conhecimento no Brasil. Marabá: Iguana; 2018. p. 29-65.

33. Valencio, N. Desastres: tecnicismos e sofrimento social. Cien Saude Colet. 2014;19(9):3631-44.

34. Feitosa AS, Alves GP. Os enquadramentos de uma cobertura: tragédia de Mariana. Vozes Diálogo. 2017;16(1):5-18.

35. Losekann C. Não foi acidente! O lugar das emoções na mobilização dos afetados pela ruptura da barragem de rejeitos da mineradora Samarco no Brasil. In: Zhouri A, editor. Mineração, violências e resistências: um campo aberto à produção do conhecimento no Brasil. Marabá: Iguana; 2018. p. 67-112.

36. Dias DL. Estereótipo e representação na construção de textos jornalísticos. In: Mari $\mathrm{H}$, et al. Análise do Discurso em perspectivas. Belo Horizonte: Fale; 2003. p. 389-96.

37. Benevides LRS. A atenção psicossocial e as intervenções geradas em contextos de desastre: a experiência de profissionais em Teresópolis [dissertação]. Rio de Janeiro: Escola Nacional de Saúde Pública Sergio Arouca; 2015.

38. Henriques AB, Porto MFS. Mineração, agricultura familiar e saúde coletiva: um estudo de caso na região de Itamarati de Minas-MG. Physis. 2015;25(4):1361-82.

39. Secretaria de Estado de Saúde de Minas Gerais. Construindo ações de Saúde do Trabalhador no âmbito das Superintendências e Gerências Regionais de Saúde. Belo Horizonte; 2011.

40. Lacaz FA, Porto MFS, Pinheiro TMM. Tragédias brasileiras contemporâneas: o caso do rompimento da barragem de rejeitos de Fundão/Samarco. Rev Bras Saude Ocup. 2017;42:e9.

41. Ministério da Fazenda (BR). Anuário estatístico de acidentes do trabalho: AEAT 2017. Brasília, DF; 2017.

42. Instituto Brasileiro de Geografia e Estatística. Síntese de indicadores sociais: uma análise das condições de vida da população brasileira: 2018. Rio de Janeiro; 2018. 